\title{
Providing stability maps for milling operations
}

\author{
Jean-Vincent Le Lan ${ }^{\mathrm{a}, \mathrm{b}, *}$, Audrey Marty ${ }^{\mathrm{a}}$, Jean-François Debongnie ${ }^{\mathrm{c}}$ \\ ${ }^{a}$ Renault S.A.S. Powertrain division, CTR B02 1 60, 67 Rue des bons raisins, 92508 Rueil Malmaison cedex, France \\ ${ }^{\mathrm{b}}$ Ecole Nationale Supérieure d'Arts et Métiers, Laboratory for Mechanics of Systems and Processes, 151 Boulevard de l'Hôpital, 75013 Paris, France \\ ${ }^{\mathrm{c}}$ Université de Liège, Manufacturing Laboratory, 1 Bis chemin des chevreuils, 4000 Liège, Belgium
}

Received 26 June 2006; received in revised form 5 September 2006; accepted 17 September 2006

Available online 20 November 2006

\begin{abstract}
This article presents a new stability prediction tool. The method is based on the dynamic behaviour of both milling tool and workpiece, computed using finite element method. Dynamic behaviour is expressed under the form of transfer functions and used to predict stability lobes at each tool position. The unconditionally stable depth of cut is then stored and displayed on a graphic representation of the machined surface under the form of colour axis, named stability map.

An application of the method on a Renault cylinder block is presented as an illustration.

(C) 2006 Elsevier Ltd. All rights reserved.
\end{abstract}

Keywords: Chatter prediction; Finite element method; Milling

\section{Introduction}

Tlusty has defined chatter as self-generative vibrations that occur when the chip width is too great versus dynamic stiffness [1]. This phenomenon leads to a bad surface aspect and high noise level. As it reduces tool life, it increases production costs. For instance, the cost due to chatter is estimated to be around $0.35 €$ per piece on a cylinder block. With such a cost, chatter prediction becomes highly necessary and a chatter criterion has to be chosen.

First evocations of chatter are due to Taylor in 1907 and then to Schlesinger in 1936. A first comprehensive study was led by Doi in 1937 [2] and then with Kato in 1956 [3]. Tlusty and Polacek published their criterion the next year [4] and Tobias proposed his chatter maps the year after [5]. During the early 1960s, Péters and Vanherck ran some tests and developed measurement techniques in order to discuss Tlusty and Tobias criterions [6]. The 1970s have shown some work on the dynamic parameters. Hanna and Tobias worked on the non-linearity of the stiffness [7] while the Péters and Vanherck team produces highly interesting

\footnotetext{
*Corresponding author. Renault S.A.S. Powertrain division, API FR CTR B02 130, 67 rue des bons raisins, 92508 CEDEX Rueil Malmaison, France. Tel.: + 33176875474 .

E-mail address: jean-vincent.le-lan@renault.com (J.-V. Le Lan).
}

thesis on the identification of dynamic parameters during the cutting operations [8,9]. At the end of 1970s, Tlusty presented his CIRP keynote paper on the topic [10]. Up to now major developments have been designed for aeronautic industry where tools are mostly more compliant than workpieces. In this way, Altintas and Budak have proposed an analytic method for computing stability lobes corresponding to Tobias's chatter maps in 1995 [11]. This work has been extended in 1998 [12] by taking the workpiece's behaviour into account under the form of compliance-damping systems in two directions. A comprehensive summary of recent developments of the topic has been proposed by Altintas and Weck under the form of a CIRP keynote [13].

Chatter cases in milling automotive parts occur mostly when the compliance of the workpiece is too high. This implies to adapt methods referenced before to this specific case. The problem is that the machined surface does not present an uniform stiffness. First attempt of prediction for this kind of operations was proposed by Masset and Belluco in 2004 [14]. They based their prediction on computing the static stiffness of the workpiece using finite element method. As the stiffness and orientation of cutting forces are varying along the machined surface, they computed a critical depth of cut that also varies along the face using Tlusty's criterion. 


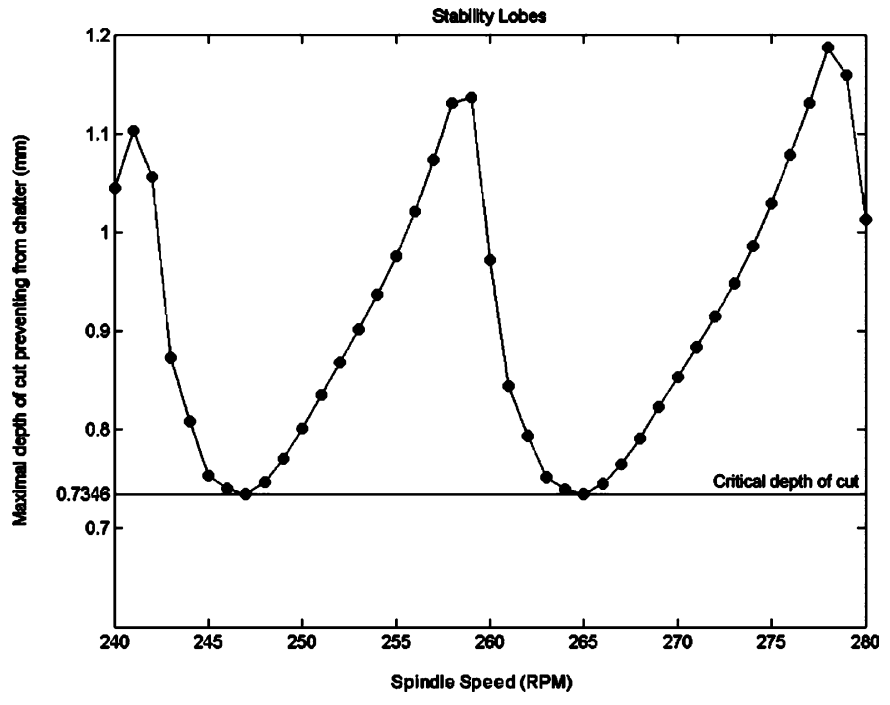

Fig. 1. Example of stability lobes and critical depth of cut.

Table 1

Cutting conditions

\begin{tabular}{ll}
\hline Tool diameter & $200 \mathrm{~mm}$ \\
Spindle Speed & $250 \mathrm{RPM}$ \\
Feed & $1900 \mathrm{~mm} / \mathrm{min}$ \\
Number of teeth & 32 \\
Tool working cutting edge angle & $45^{\circ}$ \\
Depth of cut (nominal) & $3 \mathrm{~mm}$ \\
\hline
\end{tabular}

The method presented in this communication is based on the work of Altintas and Budak [12] and uses the dynamic behaviour of both workpiece and milling tool to compute a critical depth of cut that varies along the machined face.

\section{Computing stability lobes using FEM}

The finite element method is very accurate for predicting dynamics of structures. The main idea here is to use its prediction capacities to predict the best cutting condition. The whole work is done in frequency domain in order to provide fast computations. Strong linearity hypothesis is done on the cutting force model. The goal of the method is mainly to provide a warning for process designers to avoid chatter. As the rotating speed of millers used are very low (around $200 \mathrm{rpm}$ ), the only result provided is the critical depth of cut. This depth of cut is defined as the maximal depth of cut that prevents chatter for any spindle speed i.e. that links all stability lobes minimums as shown in Fig. 1. As the used model is linear, this depth of cut is constant for any spindle speed.

If $b$ represents the chip width and $h$ is the chip thickness, a linear model for the cutting force can be obtain from the derivation of the Kienzle model at point $(b, h)$. Furthermore, a cutting force variation due to a small variation of $h$, dh is:

$\mathrm{d} F=K b \mathrm{~d} h$

The variation $\mathrm{d} h$ comes from the difference of the vibration previously let by the tool, the outer modulation on the
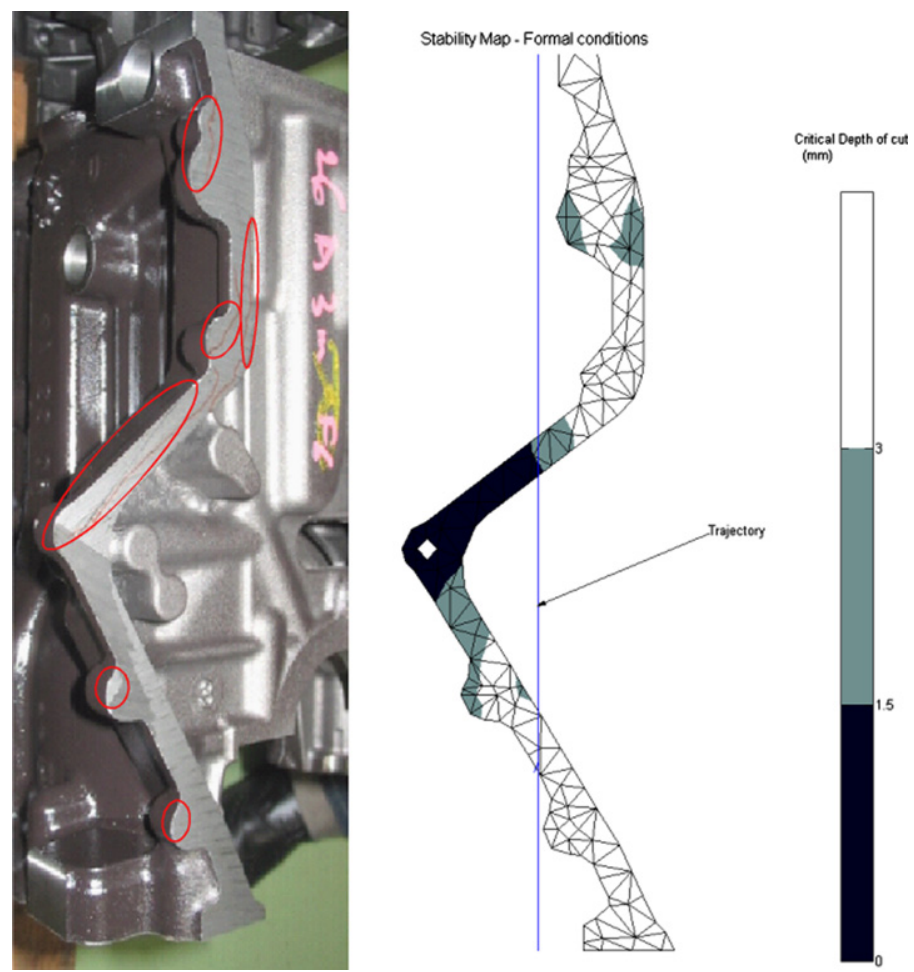

Fig. 2. Left: A formal test part chatter marks are circled. Right: Corresponding/Stability map. 
chip, and the instant vibration, the inner modulation. These vibrations are due to both workpiece and tool dynamics, excited by the cutting force variations. The mechanical system forms a loop which stability limits are studied.

Dynamics of both tool and workpiece are expressed under the form of a transfer matrix linking modulation to cutting force. A time delay closes the loop. If $\underline{\Delta}$ represents the modulation vector, $T$ the time delay, $\omega_{c}$ a chosen chatter pulsation and $\underline{\underline{\Psi}}$ the transfer matrix,

$$
\underline{\Delta}=\left[1-\mathrm{e}^{-\mathrm{i} \omega_{c} T}\right] \underline{\underline{\Psi}} \underline{\mathrm{d} F}
$$

As $\underline{\Delta}$ and $\mathrm{d} h$ are linked, an eigenvalue problem appears. Its resolution gives $b_{\text {lim }}$, the $b$ value that prevents from chatter at pulsation $\omega_{c}$ and that is valid for many rotating speed corresponding to harmonics. All details can be found in [12].

The evolution brought by FEM use is that $\underline{\underline{\Psi}}$ evolves along the tool path and each immersed tooth may encounter different dynamic compliances. This leads to as many dynamic systems - that are interacting with each other-as there are immersed cutters. Considering three possible directions for vibrations, if there is only one cutter in material, the size of $\underline{\Psi}$ is $3 \times 3$. For $n$ immersed systems, $\underline{\Psi}$ enlarges itself to $3 n \times 3 n$.

In practice, only one stability lobe is computed at each node. As the literature shows no good correlation between predicted and true stability lobes positions on the spindle speed axis for low values, only the minimum value is stored. This value corresponds to the critical depth of cut.

Physically, this method can be used if the distance between two nodes is not too small comparatively to the wavelength of the chatter modulation.

\section{Example of stability map}

As presented, the method is not suitable for very accurate predictions but is useful for process planners in order to avoid most chatter cutting condition. The result provided is the critical depth of cut of each node of the machined surface. It can be presented under the form of a coloured map that immediately shows weaknesses of the fixturing system for instance or the workpiece structure.

The milling of one face of the crankcase of the new Renault's $2.0 \mathrm{dCi}$ diesel engine $(130 \mathrm{~kW}, 360 \mathrm{Nm}$ at $2000 \mathrm{rpm}$, Euro 4) is presented. The crankcase was originally developed to be mass optimized for its functionality, which resulted in several compliant faces, difficult to face mill. The cutting conditions are summarized in Table 1. As the first attempts where showing chatter on one face, the presented chatter prediction tool has been used to propose a new fixture system and some parts evolution to prevent from chatter.
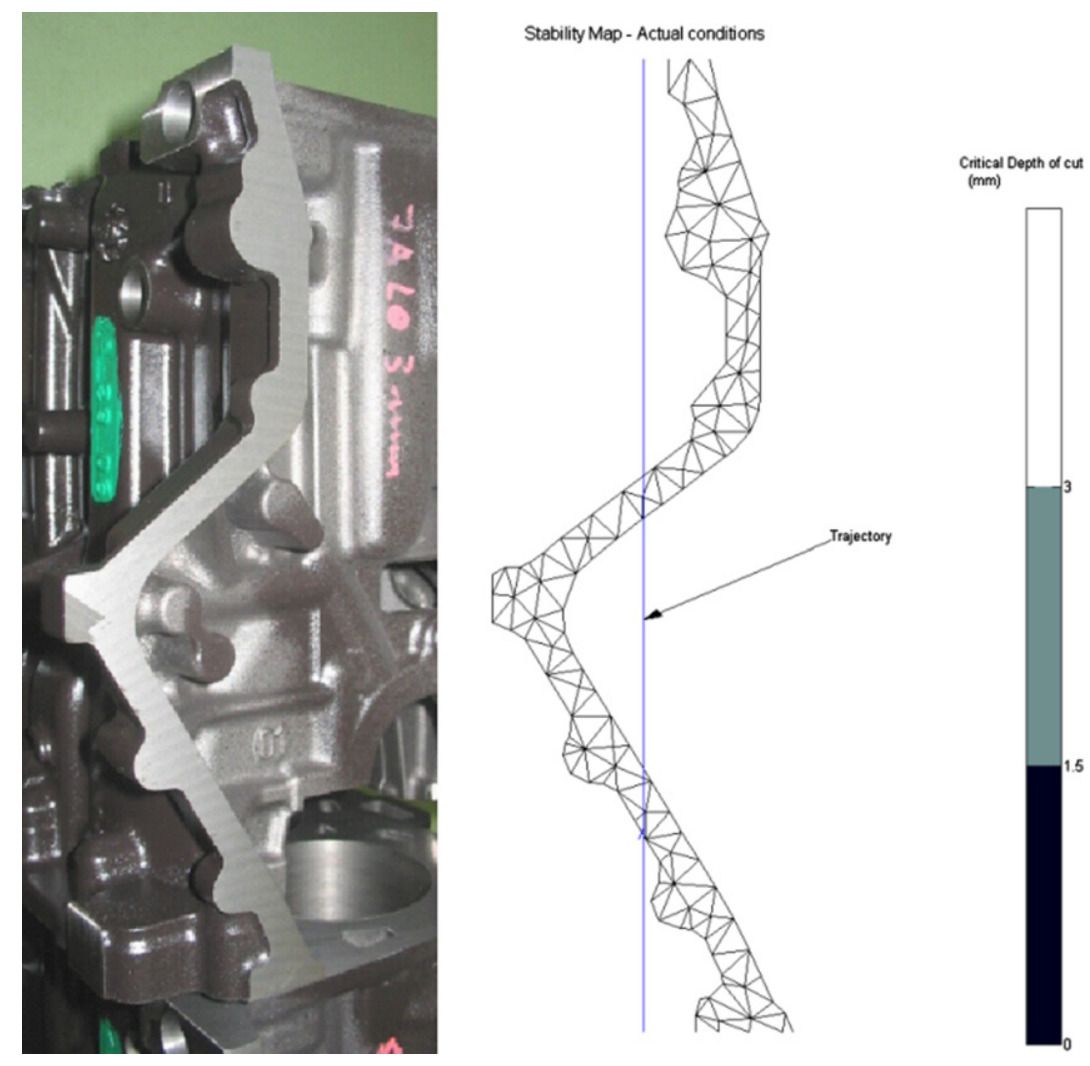

Fig. 3. Left: An actual test part. Right: Corresponding stability map. 
Fig. 2 shows the formal stability map. The cycle time is very constrained and allows only two passes. Considering the result of Fig. 2, the left part of the face will present chatter even with a $1.5 \mathrm{~mm}$ depth of cut. Some changes have been done in the part design and a new fixture system holds the left corner of the workpiece resulting in the stability map shown in Fig. 3. This figure shows that no chatter occurs under a $1.5 \mathrm{~mm}$ depth of cut. Tests have been run to confirm the computation and showed good agreement.

\section{Conclusions}

The main objective of this work is to provide very quickly an indication on chatter. As it is based on finite elements method, it can be used for process planning saving expensive prototyping.

The stability map is very easy to understand and facilitates collaborative negotiations between process planners and product designers.

Frequency domain approaches allow very fast computations. In presented cases (around 250000 nodes for the workpiece), on Renault's shared calculators (IBM p655 84 processors 336 GO RAM and 9 TO hard drive), the computation of eigenmodes with a commercial solver takes only $3200 \mathrm{~s}$ and the treatments resulting in stability maps need $90 \mathrm{~s}$ on a common computer.

\section{Acknowledgements}

The authors would like to thank Walter Belluco and Luc Masset for their support.

\section{References}

[1] J. Tlusty, Manufacturing Process and Equipment, Prentice-Hall, 2001.

[2] Doi, Chatter of lathe tool, Theoritical Society of Mechanical Engineering 3(10) 1937, p 94

[3] Doi, Kato, Chatter vibration of lathe tools, transactions of the ASME 78 (1956)

[4] J. Tlusty, M. Polacek, Beispiele der Behandlung der selbsterregten Schwingung der Werkzeugmaschinen, FoKoMa, HanserVerlag, 1957

[5] S.A. Tobias, W. Fishwick, Theory of regenerative machine tool chatter, Engineering 258 (1958).

[6] J. Péters, P. Vanherck, Un critère de stabilité dynamique pour machine-outils, CRIF, 1962

[7] N.H. Hanna, S.A. Tobias, A theory of nonlinear regenerative chatter, Journal of Engineering for Industry, transaction of the ASME (1974)

[8] H.S. Luthra, Influence of the dynamic and machining para meters in dynamic characteristics of a turning process and prediction of chatter, PhD Thesis, Katholieke Universiteit te Leuven, 1974

[9] R. Radharamanan, The measurement of the dynamic cutting coefficients and the analysis of chatter behaviour in turning, $\mathrm{PhD}$ Thesis, Katholieke Universiteit te Leuven, 1977

[10] J. Tlusty, Analysis of the state of research in cutting dynamics, Annals of the CIRP 27/2 (1978) 583-589.

[11] Y. Altintas, E. Budak, Analytical prediction of stability lobes in milling, Annals of the CIRP 44/1 (1995) 357-362.

[12] E. Budak, Y. Altintas, Analytical prediction of chatter stability in milling - Part I: general formulation, Journal of Dynamic Systems, Transactions of the ASME 120 (1998) 31-36.

[13] Y. Altintas, M. Weck, Chatter stability of metal cutting and grinding, Annals of the CIRP, 53/2 (2004) 619:642

[14] L. Masset, J.F. Debongnie, W. Belluco, Chatter maps for process design of powertrain components, in: Proceedings of the seventh CIRP International Workshop on Modelling of Machining Operations, 2004, pp. 251-258. 